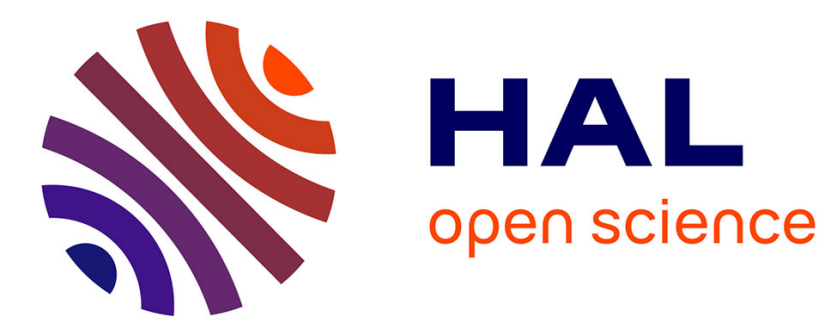

\title{
NUMERICAL SIMULATION OF SPALLATION IN BRITTLE SOLIDS
}

\author{
Z. Wang, F. Huang, S. Yun
}

\section{To cite this version:}

Z. Wang, F. Huang, S. Yun. NUMERICAL SIMULATION OF SPALLATION IN BRITTLE SOLIDS. Journal de Physique IV Proceedings, 1991, 01 (C3), pp.C3-577-C3-580. 10.1051/jp4:1991381 . jpa00250526

\section{HAL Id: jpa-00250526 https://hal.science/jpa-00250526}

Submitted on 1 Jan 1991

HAL is a multi-disciplinary open access archive for the deposit and dissemination of scientific research documents, whether they are published or not. The documents may come from teaching and research institutions in France or abroad, or from public or private research centers.
L'archive ouverte pluridisciplinaire HAL, est destinée au dépôt et à la diffusion de documents scientifiques de niveau recherche, publiés ou non, émanant des établissements d'enseignement et de recherche français ou étrangers, des laboratoires publics ou privés. 


\title{
NUMERICAL SIMULATION OF SPALLATION IN BRITTLE SOLIDS
}

\author{
Z. WANG, F. HUANG and S. YUN \\ Mechanics Engineering Department, Beijing Institute of \\ Technology, P.O. Box 327, Beijing 100081, China
}

\begin{abstract}
Un modèle de rupture dynamique fragile de matériaux endommagés est décrit dans cette communication. La porosité $\Phi$ est utilisée pour décrire la rupture fragile par nucléation, croissance, coalescence de micro-fissures et écaillage. Des simulations numériques sont réalisées avec ce modèle. Les résultats obtenus montrent un meilleur accord avec les résultats expérimentaux que ceux de Cochran, [1].
\end{abstract}

\begin{abstract}
A dynamic brittle fracture model of damaged solids is developed in this paper. The porosity $\Phi$ is used for describing the brittle fracture process which consists of microcrack nucleation, microcrack growth, microcrack coaleacence and spall formation. Numerical simulation of spall process is carried out with the model. The numerical results are much more better in agreement with the experiment results than Cochran's ${ }^{\text {[1] }}$.
\end{abstract}

\section{Introduction}

In general, the fracture mechanisms are divided into three kinds: ductile fracture mode, brittle fracture mode and mixed mode. Low temperature or high strain rate encourage brittle mocrocracking, whereas high temperature or low rates favor ductile void nucleation and growth. On the basis of experiment, Seaman et al. ${ }^{\text {[2] }}$ developed a dynamic brittle fracture model by the microstatistical approach. The simulations agreed well with the experiment results and could model the failure process by the nucleation, growth, and coalescence of the microcracks. But Seaman's model is so complex that it is difficult for utilization as many unknown parameters are needed to be determined by experiment. Cochran ${ }^{[1]}$ proposed a simple dynamic fracture model by two internal variables, namely, the spall strength and the critical porosity. Although the model is simple, it can simulate well the experiment results.

A dynamic brittle fracture model was given in this paper. The porosity $\Phi$ was used for describing the brittle fracture process. The material parameters of damage materials were also described by the function of porosity $\Phi$. The computer simulations by our model agreed well with Cochran's experiment.

\section{Fracture model}

The porosity $\Phi$ which is described by two internal variables, namely, the density of microcracks and the average size of microcrack, was chosen for describing the brittle fracture process. The fundamental equation of $\Phi$ was given by Perzyna ${ }^{\text {[3] }}$

$$
\Phi=A N R^{3}
$$

where $\mathbf{A}$ is the material constant related with the shape of microcrack. 
The density of microcracks $\mathrm{N}$ and the average size of microcrack were given as

$$
\begin{aligned}
& \dot{N}= \begin{cases}\dot{N}_{0}\left\{\exp \left[\frac{m\left(\sigma-\sigma_{N}\right)}{k \theta}\right]-1\right\} & \sigma>\sigma_{\theta} \\
0 & \sigma \leqslant \sigma_{N}\end{cases} \\
& \dot{R}= \begin{cases}\frac{\left(\sigma-\sigma_{G}\right) R}{\eta} & \sigma>\sigma_{G} \\
0 & \sigma \leqslant \sigma_{G}\end{cases}
\end{aligned}
$$

where $\dot{N}_{0}$, m are the material constants, $\sigma$ denotes the stress, $\mathrm{k}$ is the Boltzmann constant, $\theta$ denotes the temperature, $\sigma_{N}$ is the nucleation threshold stress, $\eta$ is called the viscosity coefficient, $\sigma_{G}$ is the microcrack growth threshold stress.

The evolution of $\Phi$ during the dynamic process is determined by the differential equation

$\dot{\Phi}=A R^{3} \dot{N}+\frac{3 \Phi \dot{R}}{R}$

Suppose $\dot{\Phi}$ is composed of $\dot{\Phi}_{n}$ (nucleation) and $\dot{\Phi}_{g}$ (growth)

$\dot{\Phi}=\dot{\Phi}_{n}+\dot{\Phi}_{g}$

Considering the growth part, we have

$\dot{\Phi}_{g}= \begin{cases}\frac{3\left(\sigma-\sigma_{g}\right) \dot{\Phi}}{\eta} & \sigma>\sigma_{g} \\ 0 & \sigma \leqslant \sigma_{g}\end{cases}$

Considering the nucleation part, we have

$\dot{\Phi}_{n} \sim \dot{N}$

or $\dot{\Phi}_{n}= \begin{cases}A_{1}\left[\exp \left(\frac{\sigma-\sigma_{N}}{A_{2}}\right)-1\right] & \sigma>\sigma_{N} \\ 0 & \sigma \leqslant \sigma_{N}\end{cases}$

where $A_{1}$ is a constant, $A_{2}$ is the material parameter, and $A_{2}=\frac{m}{k \theta}$.

Then the evolution equation (5) takes the form

$\dot{\Phi}=A_{1}\left[\exp \left(\frac{\left(\sigma-\sigma_{N}\right)}{A_{2}}\right)-1\right]+3\left(\sigma-\sigma_{G}\right) \frac{\Phi}{\eta}$

In order to minimize the unknown parameters, the simplicity was given for $\dot{\phi}_{n}$

$$
\begin{aligned}
\dot{\Phi}_{n}= & A_{1}\left(1+\frac{\sigma-\sigma_{n}}{A_{2}}+\ldots-1\right) \\
& \approx \frac{A_{1}}{A_{2}}\left(\sigma-\sigma_{n}\right) \\
& =B\left(\sigma-\sigma_{n}\right)
\end{aligned}
$$

The final evolution equation of $\Phi$ then takes the form

$$
\dot{\Phi}=B\left(\sigma-\sigma_{n}\right)+3\left(\sigma-\sigma_{G}\right) \frac{\Phi}{\eta}
$$


where $B$ is constant which can be determined by computer trial calculation, $\sigma_{G}=\sigma_{n}$ is usually chosen in the fol lowing form

$$
\sigma_{n}=0.5 \rho c \Delta v
$$

where $\rho$ is the density, $\mathrm{c}$ is the sound velocity, $\Delta \mathrm{v}$ is the pullback velocity which can be determined in the measured free-surface velocity.

The growth and coalescence of microcracks, or the damage that occurs in solids during dynamic process is presumed to affect both the yield strength and the effective shear or bulk moduli of material. As the measure of damage we define a strength function

$$
F=1-\left(\frac{\Phi}{\Phi}\right)^{n}
$$

where $\Phi$ is the porosity, $\Phi_{e r}$ is the critical porosity, $\mathbf{n}$ is a constant.

$F$ is used to characterize the degraded shear and bulk moduli by the presence of microcracks. The corresponding expressions are

$$
\begin{aligned}
& Y=F Y_{0} \\
& \mu=F \mu_{0} \\
& K=F K_{0}
\end{aligned}
$$

where $Y_{0}, \mathrm{Y}$ are the yield strengths undamaged and damaged, $\mu_{0}, \mu$ are the shear moduli undamaged and damaged, $K_{0}, \mathrm{~K}$ are the bulk moduli undamaged and damaged.

The relation between the average macroscopic pressure and the pressure without microcracks is given by

$$
P=(1-\Phi) P_{s}[(1-\Phi) V, E]
$$

\section{Numerical Simulations}

Our model was implemented into a one-dimensional finite-differential code. The Runge-Kutta scheme was developed to solve the evolution equation of porosity $\Phi$ (formula (10)). For model validation, Cochran's experiment results ${ }^{[1]}$ were considered for simulations. The fracturehappens in the cell when its porosity exceeds the critical porosity, namely $\Phi>\Phi_{c r i}$, and at this time the strength function $\mathrm{F}$ equals zero. The mechanical parameters in the fracture cell are considered zero in the simulation. The simulation results by our model are shown in Figure 1. The results simulated by Cochran's model are also given in the Figures. The simulations by our model agree well with the experiment and are better in agreement with the experiment than Cochran's. In order to evaluate the numerical stability and accuracy, different time steps were chosen in each run as shown in Figure 2. It can be seen that the time step had no influence on the free-surface velocity.

\section{Summary}

A brittle fracture model is developed which works well in describing spall fracture of uranium. The model is based on the porosity $\Phi$ which is a function of the density of microcracks and the average size of microcrack. The evolution equation of $\Phi$ is postulated in this paper. The model can describe the nucleation, growth, coalescence of microcracks and fracture process. The simulations agree well with the experiments. From the simulation we can see the presented model is appropriate to the dynamic brittle fracture process. 


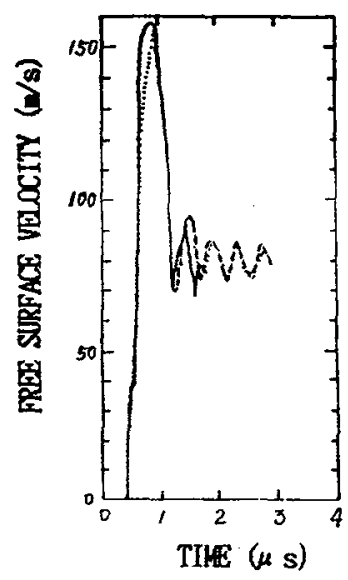

Fig.1.1 Experiment 2

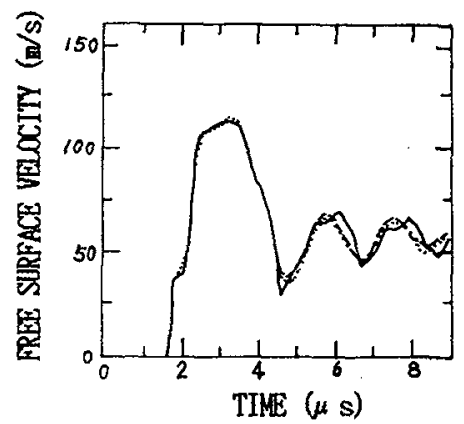

Fig.1.3 Experiment 9

Fig.1 Comparison of calculated (dashed line) and measured (dotted line) and Cochran's (solid line) in different experiments

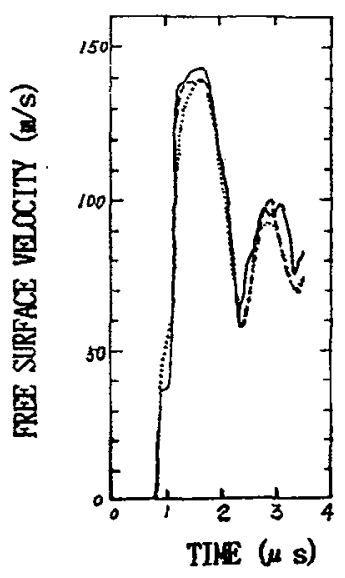

Fig.1.2 Experiment 5

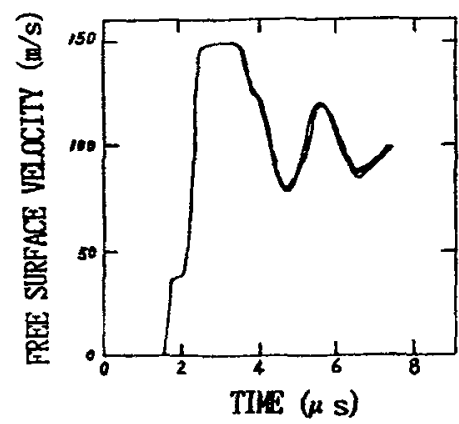

Fig.2 The effect of time step on the numerical solutions

\section{References}

[1] Cochran,S. et al., J. Appl. Phys., Vol.48, No.7, P.2729, 1977.

[2] Curran,D.R. et al., Physics Reports, Vol.147, No.5-6, 1987.

[3] Perzyna,P., Arch. Mech., Vol.38, No.5-6, P.725,1986. 